Abstracta Iranica Abstracta Iranica

Revue bibliographique pour le domaine irano-aryen

Volume 24 | 2003

Comptes rendus des publications de 2001

\title{
« Hand Made : Pour une anthropologie du geste musical ». Cahiers de musiques traditionnelles, $\mathrm{n}^{\circ} 14$, (2001), pp. 39-68.
}

Rédaction et Sāsān Fāțemī

\section{(2) OpenEdition}

Journals

Édition électronique

URL : http://journals.openedition.org/abstractairanica/35006

ISSN : 1961-960X

Éditeur :

CNRS (UMR 7528 Mondes iraniens et indiens), Éditions de l'IFRI

Édition imprimée

Date de publication : 15 mai 2003

ISSN : 0240-8910

Référence électronique

Rédaction et Sāsān Fāțemī, « « Hand Made : Pour une anthropologie du geste musical ». Cahiers de musiques traditionnelles, $n^{\circ}$ 14, (2001), pp. 39-68. ", Abstracta Iranica [En ligne], Volume 24 | 2003, document 370, mis en ligne le 05 janvier 2010, consulté le 25 septembre 2020. URL : http:// journals.openedition.org/abstractairanica/35006

Ce document a été généré automatiquement le 25 septembre 2020.

Tous droits réservés 
« Hand Made : Pour une anthropologie du geste musical ». Cahiers de musiques traditionnelles, $\mathrm{n}^{\circ}$ 14, (2001), pp. 39-68.

\author{
Rédaction et Sāsān Fāțemī
}

Cette étude comparative couvrant les pratiques musicales de l'Asie intérieure, dégage clairement deux modèles bien distincts susceptibles d'être affinés par les données de l'anthropologie culturelle: nomade et turcique d'un côté, sédentaire et iranien de l'autre. Tous les aspects du geste musical sont passés ici en revue dans le cadre des cultures de l'Asie intérieure : la posture ou position, le toucher, le rapport au corps et la valeur sémantique du mouvement physique, la réduction des mouvements des cinq doigts à un système binaire de coups de plectre, la grammaire rythmique des luths à deux cordes. On y trouve d'abord une esquisse de catégorisation: geste fonctionnel, expressif, acrobatique, suggestif, chorégraphique, etc. Puis, de ce survol se dessinent quelques lignes de partage : - au niveau conceptuel, entre instruments hétérogènes et homogènes, entre temps lisse et temps strié, entre esthétique de l'asymétrie et de la symétrie, - dans les pratiques, entre la tendance au contrepoint à deux voix chez les nomades türks vs le bourdon fixe chez les sédentaires iraniens, l'absence de danse (nomades) vs la présence de la danse (sédentaires), les gestes amples et extravertis chez les premiers vs la sobriété et la maîtrise de soi chez les seconds. 
INDEX

Thèmes : 17.1.Musique

\section{AUTEURS}

\section{RÉDACTION}

Directeur de la revue et secrétariats - Paris et Téhéran

\section{SĀSĀN FĀTEMĪ}

Université de Téhéran 